\title{
Advanced methods for computation of electrical parameters for overhead transmission lines
}

\author{
Matej Cenký, Jozef Bendík, Žaneta Eleschová *
}

\begin{abstract}
This paper is aimed on the calculation of the electrical parameters of the overhead transmission lines. Standard transposition and untransposed calculations are presented, also with results on the existing power line on $110 \mathrm{kV}$ voltage level and known measured values of the electrical parameters. These measured parameters are used as the reference values. A presumption is made, that through more complex calculation one can achieve better results. The real results achieved are presented and compared with an ideal presumption
\end{abstract}

K e y w or d s: overhead power lines, electrical parameters, complex depth

\section{Introduction}

Power engineering requirements are today more complex than ever before. Various tower structures, different voltage levels or even rate currents are a challenge for precise calculations. One of the most common issues is the computation of the electrical parameters of the overhead transmission lines in general. The transposition of lines (an actual geometrical arrangement of the lines) could affect the current or voltage asymmetry. A different approach is recommended when the line is transposed only partially or is fully untransposed. In the latter one cannot neglect the geometry of the tower in a way the computations in common do.

The article presents a comparison of results achieved using a self-made software ELPAM MultiGeo and standard computational method concluded from the Carsons equations $[1,2]$ for perfectly transposed lines. All parameters to be compared with our evaluations were provided by SAG Elektrovod, a.s. as measured on a power line, like line number 8823 (Zlaté Moravce - Levice). These values are considered as a reference for both methods. The motivation for this work was to establish a simplified but still reliable method as a practical need.

\section{Computational background}

In high voltage power systems, it is advised to use the AC resistance instead of the DC resistance of a conductors [3,4]. This is important for computing the series impedance matrix of the transmission system due to not negligible error, when the skin effect is not taken into the account. This inaccuracy is rising together with the wire conductivity. When calculating the lower voltage systems (approximately up to $110 \mathrm{kV}$ ), the error is around a few per cent and could be ignored, in some cases.
Nomenclature $f(\mathrm{~Hz})$ - nominal frequency $r_{c}(\mathrm{~mm})$ - radius of the conductor $r_{\mathrm{GW}}(\mathrm{mm})$ - radius of the ground wires $N$ - number of conductors $M$ - number of ground wires $S A G_{\mathrm{MC}}(\mathrm{m})$ - maximum sag of conductors $S A G_{\mathrm{MGW}}(\mathrm{m})$ - maximum sag of ground wires

Using the ground wires, the number of values that are needed to compute is increased. For example, $N \times N$ impedance matrix will expand to size $(N+M) \times(N+M)$, with $N$ conductors, and $M$ ground wires. However, the smaller $(N \times N)$ matrices are much more comfortable to use especially for connected sections of transmission lines with different structure. The technique known as Kron Reduction [4,5] is therefore introduced based on an assumption, that the ground wires have a zero potential with respect to the ground.

As discussed in detail in [6], the transformation matrices are used to transform the phase quantity matrices to the sequence and backward ones.

\section{Approximative method}

This method is widely used with mostly correct results. It is more deeply discussed in [7-10]. The results achieved by this technique would be accurate if the power line is perfectly transposed. Prerequisites are therefore almost never fulfilled and then - the precision suffers also. The positive of this method is its simplicity and ease of getting at least the approximate values. The negative is possibly more inaccurately calculated values. The impedances are given below as self ("ii") and mutual ("ik") ones

$$
\begin{gathered}
\mathcal{Z}_{i i}=R_{A C}+R_{g}+j \omega \frac{\mu_{0}}{2 \pi} \ln \frac{D_{g}}{\xi r_{i}} \\
\mathcal{Z}_{i k}=R_{g}+j \omega \frac{\mu_{0}}{2 \pi} \ln \frac{D_{g}}{D_{i k}}
\end{gathered}
$$

* Institute of Power and Applied Electrical Engineering, Faculty of Electrical Engineering and Information Technology, Slovak University of Technology, Ilkovičova 3, 81219 Bratislava, Slovakia, matej.cenky@stuba.sk 
where: $D_{\mathrm{G}}(\mathrm{m})$ - depth of the current earth return in the ground $\xi$ - construction parameter of the conductor $r_{i}(\mathrm{~m})$ - radius of the conductor $i R_{\mathrm{AC}}(\mathrm{m})$ - resistance of the conductor under alternate current load $R_{\mathrm{g}}(\mathrm{m})-$ resistance of the homogenous ground.

The model of the two-conductor power line, used in approximative computational method is shown in Fig. 1.

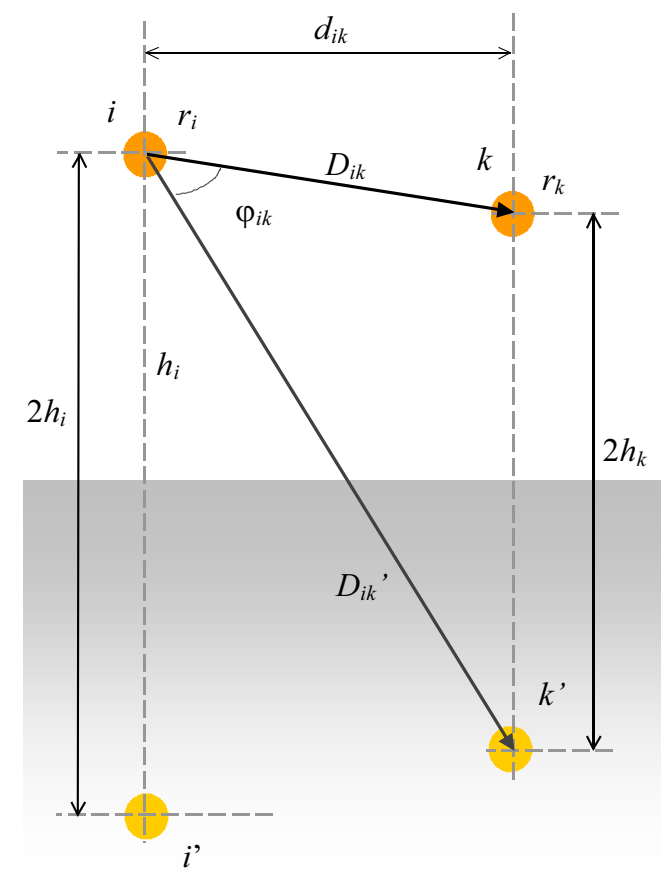

Fig. 1. Geometry of two conductor power line in cross section used in approximative method

The admittance of the line is defined in the same manner in both computational methods. Kelvin's method of mirroring will be used, the details of which are not discussed here.

\section{CDER Method}

The CDER computational method (Complex Depth Earth Return) is an approach, proposed in 1960's by Dubanton [11], later contributing by Gary [12] and Deri [13]. The results obtained by this method - inserting the complex depth - are for low frequencies almost identical (error up to $3 \%$ for $50 \mathrm{~Hz}$ ) with those from original and robust Carson's method [14].

Equations for the impedance of a line are then modified as

$$
\begin{gathered}
\mathcal{Z}_{i i}=R_{A C}+j \omega \frac{\mu_{0}}{2 \pi} \ln \frac{2\left(h_{i}+\mathfrak{p}\right)}{\xi r_{i}} \\
\mathcal{Z}_{i k}=j \omega \frac{\mu_{0}}{2 \pi} \ln \frac{D_{i k^{\prime}}}{D_{i k}} \\
\mathfrak{p}=\sqrt{\frac{\rho}{j \omega \mu}}
\end{gathered}
$$

where $\mathfrak{p}$ is a complex number the so called complex penetration depth.

Note that

$$
\delta=\sqrt{\frac{2 \rho}{\omega \mu}}
$$

is the commonly known as the penetration depth of an electromagnetic wave in a conducting media. Here $\omega$ is the angular frequency, $\rho(\Omega \mathrm{m})$ is the resistivity of the ground and $\mu$ is the ground permeability, which could be assumed $h \mu_{0}=4 \pi \times 10^{-7} \mathrm{H} / \mathrm{m}$. The heights $h_{i}$ and $h_{k}$ are given by the geometry of the power line as shown in Fig. 1.

A computational program was made by Cenky [1] which is used also in this paper. This program contains CDER method and computes electrical parameters of the line in form of matrices and sequence representation.

\section{Admittance of the line}

Computational approach for admittance of the power lines is consistent $[2,7]$ and introduces the Kelvin method of mirroring. The calculation steps are as follows:

1 Form the Maxwell potential coefficients matrix of the line 2 Invert the formed matrix to achieve the capacitance matrix 3 Compute the reactance matrix from the capacitance matrix

$$
\begin{gathered}
{[P]=\left[\begin{array}{lll}
P_{11} & P_{12} & P_{13} \\
P_{21} & P_{22} & P_{23} \\
P_{31} & P_{32} & P_{33}
\end{array}\right]} \\
P_{i i}=\frac{1}{2 \pi \varepsilon_{0}} \ln \frac{2 h_{i}}{r_{i}} \\
P_{i k}=\frac{1}{2 \pi \varepsilon_{0}} \ln \frac{D_{i k^{\prime}}}{D_{i k}}
\end{gathered}
$$

Where $\epsilon_{0}=8.854 \times 10^{-12}(\mathrm{~F} / \mathrm{m})$ is the permittivity of free space. Although the real part is missing in this admittance, it does not cause a substantial error in frequency range of interest.

\section{Investigated object}

The overhead transmission line is a distribution line on $110 \mathrm{kV}$ voltage level. The measured reference parameters were kindly provided by company SAG Elektrovod, a.s. The line itself consists of 102 towers, in which 100 is of a common type "F" shown in Figure 2. It should be noted, that the 2 "Portal" type towers were due to the low importance neglected. 


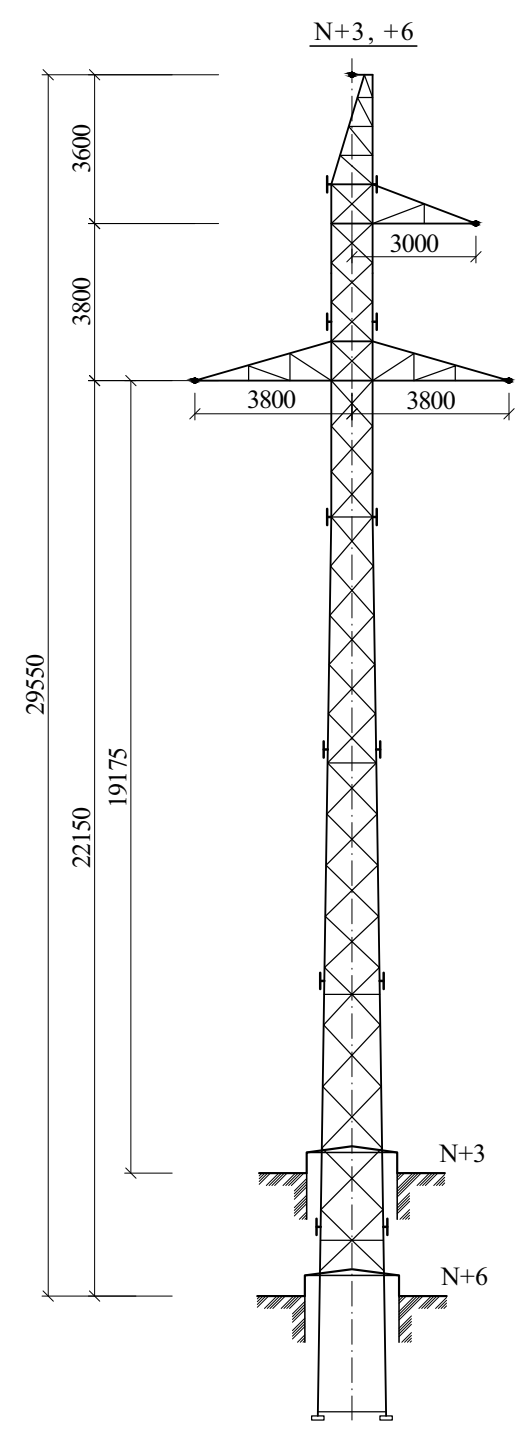

Fig. 2. Suspension tower type "F" used in computations

The line has multiple types of phase conductors as well as multiple types of ground wires across the whole length. The towers are also not only consisting of only one height, therefore were created various line models.

\section{Measurement of electrical parameters}

Measured positive and zero sequence electrical parameters (resistance, reactance and susceptance) of the investigated line were obtained with the help of Omicron CPC 100 and CU1 + CP GB1 devices [15] as was the information provided by engineers from above mentioned company. First unit is used as a power source and the second one as measurement tool and grounding as well (for the unexpected events can conduct the current up to $30 \mathrm{kA}$ to the ground). For the measurement, the line must be disconnected on both ends from the power grid. Omicron devices are then in series connected to one end of the line, while the second end is grounded. More de- tailed information about this technique can be found also on Omicron official website.

\section{Line models}

\section{(a) most common tower}

This method is widely used as a quick estimation of the electrical line parameters. The parts of a line with different phase conductors and ground wires are computed separately and then, with a help of weighted average (depending on the length of the section) the final electrical parameters are obtained. The computation is the simplest, the results most inaccurate.

\section{(b) various height of towers}

In comparison with the above-mentioned model various heights of suspension towers on the line were considered. In a group, created for each height, the most common phase conductor and ground wire were evaluated. In these groups the weighted average of electrical parameters was obtained to achieve the typical values as of the whole line. This method should give reliable results concerning the electrical parameters in spite of not considering the different height of individual towers.

\section{(c) average height of towers}

An average height of all the towers in the line is obtained and average suspension tower formed. Then the procedure described in paragraph a) is applied. This method is expected to be the most accurate, because of the coverage of all computation variables such as: various phase conductors, ground wires and all the suspension tower heights.

\section{Results}

Results from both computational methods and all three approaches are quoted here. The numbers on the end of the each table denotes: (1) - standard approximated computation, (2) - CDER method computation, (3) - measured values.

Table 1. Results from approach with most common tower approach (a)

\begin{tabular}{cccccc}
\hline$R$ & $X$ & $B$ & $R_{0}$ & $X_{0}$ & No \\
$\Omega / \mathrm{km}$ & $\Omega / \mathrm{km}$ & $\mu \mathrm{S} / \mathrm{km}$ & $\Omega / \mathrm{km}$ & $\Omega / \mathrm{km}$ & - \\
\hline 0.1938 & 0.4282 & 2.65 & 0.4143 & 1.0463 & 1 \\
0.1954 & 0.4278 & 2.63 & 0.4438 & 1.1130 & 2 \\
0.1964 & 0.4139 & N/A & 0.3742 & 0.9649 & 3 \\
\hline
\end{tabular}




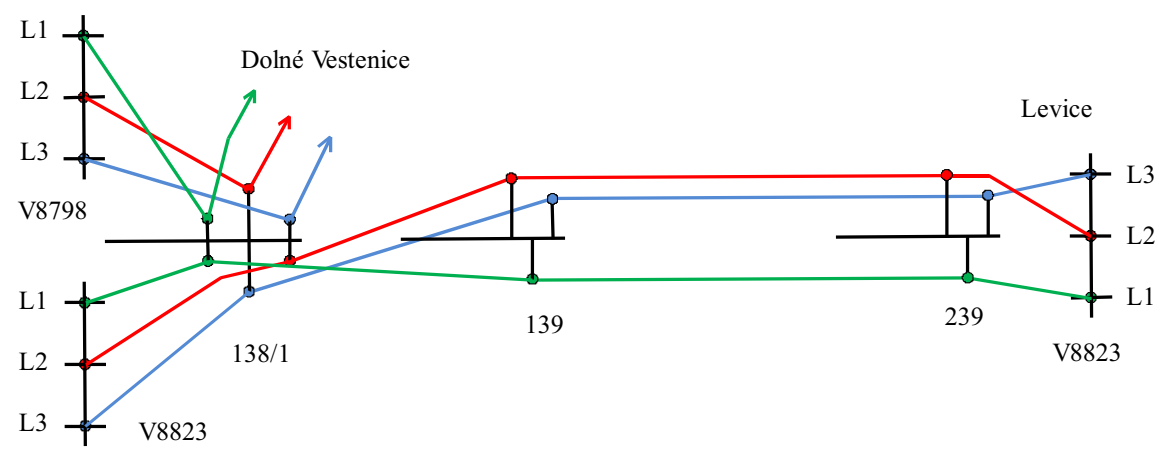

Fig. 3. The layout of the line that is similar to real power line in Slovakia

Table 2. Difference between measured and calculated electrical parameters - approach a

\begin{tabular}{cccccc}
\hline$\Delta R$ & $\Delta X$ & $\Delta B$ & $\Delta R_{0}$ & $\Delta X_{0}$ & No \\
$\%$ & $\%$ & $\%$ & $\%$ & $\%$ & - \\
1.307 & 3.460 & N/A & 10.704 & 8.441 & 1 \\
0.522 & 3.364 & N/A & 18.587 & 15.350 & 2 \\
\hline
\end{tabular}

Table 3. Results from approach with various tower height approach (b)

\begin{tabular}{cccccc}
\hline$R$ & $X$ & $B$ & $R_{0}$ & $X_{0}$ & No \\
$\Omega / \mathrm{km}$ & $\Omega / \mathrm{km}$ & $\mu \mathrm{S} / \mathrm{km}$ & $\Omega / \mathrm{km}$ & $\Omega / \mathrm{km}$ & - \\
\hline 0.1961 & 0.4286 & 2.52 & 0.4062 & 1.0377 & 1 \\
0.1981 & 0.4282 & 2.67 & 0.4325 & 1.1015 & 2 \\
0.1964 & 0.4139 & N $/ \mathrm{A}$ & 0.3742 & 0.9649 & 3 \\
\hline
\end{tabular}

Table 4. Difference between measured and calculated electrical parameters - approach (b)

\begin{tabular}{cccccc}
\hline$\Delta R$ & $\Delta X$ & $\Delta B$ & $\Delta R_{0}$ & $\Delta X_{0}$ & No \\
$\%$ & $\%$ & $\%$ & $\%$ & $\%$ & - \\
\hline 0.141 & 3.562 & N/A & 8.537 & 7.547 & 1 \\
0.840 & 3.461 & N/A & 15.561 & 14.163 & 2 \\
\hline
\end{tabular}

Table 5. Results from approach with average height of the towers approach (c)

\begin{tabular}{cccccc}
\hline$R$ & $X$ & $B$ & $R_{0}$ & $X_{0}$ & No \\
\hline$\Omega / \mathrm{km}$ & $\Omega / \mathrm{km}$ & $\mu \mathrm{S} / \mathrm{km}$ & $\Omega / \mathrm{km}$ & $\Omega / \mathrm{km}$ & - \\
0.1939 & 0.4282 & 2.77 & 0.4147 & 1.0447 & 1 \\
0.1954 & 0.4278 & 2.57 & 0.4445 & 1.1112 & 2 \\
\hline
\end{tabular}

Table 6. Difference between measured and calculated electrical parameters - approach (c)

\begin{tabular}{cccccc}
\hline$\Delta R$ & $\Delta X$ & $\Delta B$ & $\Delta R_{0}$ & $\Delta X_{0}$ & $N o$ \\
$\%$ & $\%$ & $\%$ & $\%$ & $\%$ & $\%$ \\
\hline 1.262 & 3.460 & N/A & 10.808 & 8.275 & 1 \\
0.518 & 3.362 & N/A & 18.767 & 15.165 & 2 \\
\hline
\end{tabular}

The average height of all the towers was set to 0.71 $m$ above the standard $\mathrm{N}+0$ suspension tower " $\mathrm{F}$ " type height.

\section{Conclusion}

It was shown that the assumption originally set in this article could not be truly justified on this particular power line. From the results obtained by both computational methods it is not clear if more complex approaches would give much more precise results of computations on the transmission lines. According to tables shown, even more precise calculations of electrical parameters have almost no impact on their accuracy in real transmission line. For example, in approach (a) and approach (c) when used the CDER method, the values are almost identical.

This fact indicates that the height of the tower is probably not crucial for the computation, instead the conductors and geometry of the tower would have the main impact. Future research in this topic is aimed to inclusion the terrain profile into computations. This is of interest, since the inspected line was mostly over flat terrain, but it may be not everywhere so.

To sum the results, more precise values for positive sequence values were obtained by CDER method and for zero sequence values by standard approximated method. This attempt has shown, that even if the line is untransposed the standard approximated computational method should be enough to satisfy the basic requirements for the electrical parameters of the line. It has been confirmed in terms of the relative short length (approx. $26 \mathrm{~km}$ ) and flat terrain. But there are more windows open. When computing short circuit currents on power lines, we can use for example the whole matrices as input values and so on. The fact that presumption of this paper wasn't fulfilled does not mean, that it can't find a proper application in other subsections of power engineering.

\section{Acknowledgements}

This publication is a result of implementation of the project: "Increase of Power Safety of the Slovak Republic" 
(ITMS: 26220220077) supported by the Research \& Development Operational Programme funded by the ERDF.

\section{REFERENCES}

[1] M. Cenký, "Electrical Parameters of HV and UHV Overhead Lines and their Influence on the Line Transposition", MSc Thesis, Slovak University of Technology, Bratislava, (2015).

[2] H. W. Dommel, "Electro Magnetic Transient Program Theory Book", Microtran Power System Analysis Corporation, Canada, (1996).

[3] W. A. Lewis and P. D. Tuttle, "The Resistance and Reactance of Aluminum Conductors, Steel Reinforced, Power Apparatus and Systems, Part III", Transactions of the American Institute of Electrical Engineers, vol. 77, no. 3 (1958), pp. 11891214.

[4] H. W. Beaty, Handbook of Electric Power Calculations, McGraw-Hill, USA, (2001).

[5] W. H. Kersting and R. K. Green, "The application of Carson's equation to the steady-state analysis of distribution feeders", Power Systems Conference and Exposition (PSCE) IEEE/PES, (2011), pp. 16.

[6] S. E. Zocholl and E. O. Schweitzer, "Introduction to Symmetrical Components", Schweitzer Engineering Laboratories Inc., Pullman: WA USA, (2004).

[7] S̆. Fecko, L. Varga and J. žiaran, External power lines (Vonkajšie silové vedenia), SVŠT Bratislava, (1990) in Slovak.

[8] C. Sabah, F. Urbani and S. Uckun, "Bloch Impedance Analysis for a Left Handed Transmission Line", Journal of Electrical Engineering, vol. 63, no. 5, (2012), pp. 310315.

[9] F. Senček and L. Syrová, "Wattmetric Method of Impedance Measurement", Journal of Electrical Engineering, vol. 50, no. 0910, (1999).

[10] M. Cen'y, J. Bendík and Ž. Eleschová, "Advanced Electrical Parameters Calculations of the Untransposed Overhead Lines Comparison to Standard Computational Methods", Proceedings of the 13th International Scientific Conference EEE 2016, Energy-Ecology-Economy 2016, vol. 13, no. 1, (2016), pp. 145149.

[11] C. Dubanton, "Approximate Calculation of Primary and Secondary Transmission Line Parameters", Zero Sequence Values, EDF Bulletin de la Direction des 'Etudes et Reserches, (1969), pp. 5362.

[12] C. Gary, "Complete Approach to Multiconductor Propagation at High Frequencies with Complex Matrices", EDF Bulletin de la Direction des 'Etudes et Reserches, no. 3/4, (1976), pp. 520.

[13] A. Deri, G. Tevan, A. Semlyen, A. And and Castanheira, "Wave Propagation Overhead Wires with Ground Return", Power Apparatus and Systems, IEEE Transactions on PAS-100, no. 8 (1981), pp. 36863693.

[14] J. R. Carson, "Wave Propagation Overhead Wires with Ground Return", Bell System Technical Journal, vol. 5, (1926), pp. 539 -554 .

[15] Impedance, Measurement, on, High-Voltage, Lines, Omicron, Corporation, available, at and https, Impedance Measurement on High-Voltage Lines", Omicron Corporation, available at https://www.omicronenergy.com/en/products/transmission lines/line-impedance-measurement/cpc-100-cp-cu1/.

Received 21 September 2016

Matej Cenký (Ing) is currently an internal $\mathrm{PhD}$ student on Slovak University of Technology on Institute of Power and Applied Electrical Engineering. His field of study is mainly the electrical parameters computation and steady state analysis of the transmission and distribution network. He is also capable of creating small programs and other useful scripts in various programming languages. He is an active author and participant on various science events. He was awarded with the price of a dean of the Slovak Technical University in Bratislava for the best student science paper in year 2015. He is also partly the member of the technical committee aimed on electrical installation and lightning protection.

Jozef Bendík (Ing) is an internal PhD student on Slovak University of Technology on Institute of Power and Applied Electrical Engineering. His field of study are electromagnetic fields of overhead power lines. He is an author of several softwares, which have been used for real calculation in phase of projecting construction of power lines. He was awarded with the Aurel Stodola prize, which grant Enel a.s., in year 2015 for the best Masterss thesis. He was also awarded with the Engineering prize, which grant Slovak Chamber of Civil Engineers, also for his Masterss thesis. He is an active author and participant on various science events. He is also partly the member of the technical committee aimed on electrical installation and lightning protection.

Žaneta Eleschová (doc, Ing, PhD) was born in 1974 in Handlová, Slovakia. She received the MSc degree in electrical engineering from the Faculty of Electrical Engineering and Information Technology of Slovak University of Technology, Bratislava, in 1997. In 2004 she successfully accomplished her PhD study. Her doctoral thesis named "Impact of Static Excitation System on Synchronous Generator Rotor Ground Fault Protection" was awarded with Werner von Siemens Excellent Award. From year 2006 on, she is working on the Institute of Power and Applied Electrical Engineering as an associate professor and as the director deputy for teaching process from year 2012. Her scientific work is aimed on steady-state and transient states in power systems and power system stability. She is a member of many grants and scientific projects in area of power engineering. Over the years she was guiding approximately 30 bachelor works, 30 master thesis and 7 doctoral thesis. She is also author or co-author of multiple university textbooks, scientific books and more than 150 contributions to international scientific conferences and journals. She is the chairman of the organizing committee of the international scientific event "Power Engineering in Slovakia." 